\title{
Nitric oxide synthase isoforms and NF-KB activity in normal and osteoarthritic human chondrocytes: Regulation by inducible nitric oxide
}

\author{
S.C. Rosa ${ }^{\mathrm{a}, \mathrm{b}}$, F. Judas ${ }^{\mathrm{c}, \mathrm{d}}$, M.C. Lopes ${ }^{\mathrm{a}, \mathrm{b}}$, A.F. Mendes ${ }^{\mathrm{a}, \mathrm{b}, *}$ \\ ${ }^{\text {a } C e n t e r ~ f o r ~ N e u r o s c i e n c e s ~ a n d ~ C e l l ~ B i o l o g y, ~ U n i v e r s i t y ~ o f ~ C o i m b r a, ~ 3004-517 ~ C o i m b r a, ~ P o r t u g a l ~}$ \\ ${ }^{\mathrm{b}}$ Faculty of Pharmacy, University of Coimbra, 3000-295 Coimbra, Portugal \\ ' Orthopedics Department, University Hospital of Coimbra, Coimbra, Portugal \\ ${ }^{\mathrm{d}}$ Faculty of Medicine, University of Coimbra, Coimbra, Portugal
}

\section{A R T I C L E I N F O}

\section{Article history:}

Received 25 February 2008

Revised 6 June 2008

Available online 17 July 2008

\section{Keywords:}

Human chondrocytes

Interleukin-1 $\beta$

$\mathrm{NF}-\kappa \mathrm{B}$

Inducible nitric oxide synthase (iNOS)

Neuronal nitric oxide synthase (nNOS)

Nitric oxide (NO)

Osteoarthritis (OA)

Protein degradation

\begin{abstract}
A B S T R A C T
To elucidate the role of endogenous inducible nitric oxide (NO) on the regulation of NF- $\kappa \mathrm{B}$ activity in human chondrocytes, we evaluated (i) the pattern of expression of the neuronal (nNOS) and inducible (iNOS) NO synthase isoforms and the basal NF- $\mathrm{B}$ activity in normal and osteoarthritic (OA) human chondrocytes, (ii) the role of cytokines and growth factors in modulating the protein levels of the two NOS isoforms, and (iii) the effect of inhibiting endogenous inducible NO production on the ability of interleukin-1 $\beta$ (IL-1) to induce NF- $\kappa B$ activation. nNOS was more frequently expressed in normal than in OA chondrocytes, whereas the opposite was found for iNOS. IL-1 induced the degradation of both enzymes, but iNOS disappeared more rapidly. Although I $\mathrm{B}-\alpha$ was present in all the normal samples and in the majority of the OA samples, NF- $\mathrm{B}$-DNA binding activity in OA chondrocytes was increased approximately twofold relatively to normal cells. Addition of a NOS inhibitor, after induction of iNOS expression, induced I $\mathrm{KB}-\alpha$ degradation and potenciated the effect of IL-1, indicating that endogenous inducible NO inhibits NF- $\kappa B$ activation. Taken together, these findings favor an inhibitory role of high NO levels on the regulation of NF- $\kappa B$ activation in chondrocytes, indicating that NF- $\kappa B$ activity is regulated, at least in part, by the balanced production of NO resulting from a dynamic process that, at any given moment, determines the availability of the constitutive and inducible NOS isoforms. Moreover, the down-regulatory role of NO on NF- $\kappa \mathrm{B}$ activation warrants caution as to the possible utilization of NO inhibitors in the therapy of $\mathrm{OA}$.
\end{abstract}

(c) 2008 Elsevier Inc. All rights reserved.

\section{Introduction}

Osteoarthritis $(\mathrm{OA})^{1}$ is a degenerative joint disease characterized by extracellular matrix degradation and cartilage destruction, accompanied by local inflammation and alterations of the subchondral bone, being strongly associated with aging [1,2]. In fact, $\mathrm{OA}$ is relatively uncommon before the age of 40 years old, increasing steeply in prevalence thereafter $[1,3]$.

Although the pathophysiology of $\mathrm{OA}$ is still incompletely understood, nitric oxide (NO) seems to contribute to the development and or progression of $\mathrm{OA}$, namely by mediating some of the catabolic responses induced by pro-inflammatory and catabolic cytokines, like interleukin-1 $\beta$ (IL-1), in chondrocytes [4-7]. The inducible isoform

\footnotetext{
* Corresponding author. Address: Center for Neurosciences and Cell Biology, University of Coimbra, 3004-517 Coimbra, Portugal. Fax: +351 239480217.

E-mail address: afmendes@ff.uc.pt (A.F. Mendes).

1 Abbreviations used: EMSA, electrophoretic mobility shift assay; IGF-1, insulin-like growth factor-1; I $\kappa \mathrm{B}-\alpha$, inhibitor of NF- $\kappa \mathrm{B}-\alpha$; IL-1, interleukin- $1 \beta$, iNOS, inducible nitric oxide synthase; L-NMMA, $N^{\mathrm{G}}$-Monomethyl-L-arginine acetate; NF- $\mathrm{KB}$, nuclear factor- $\kappa \mathrm{B}$; nNOS, neuronal nitric oxide synthase; NO, nitric oxide; OA, osteoarthritis, TGF- $\beta$, transforming growth factor- $\beta$; TNF- $\alpha$, tumor necrosis factor- $\alpha$.
}

of the NO synthase (iNOS or NOS II), whose expression is potently induced by pro-inflammatory cytokines through activation of the transcription factor, nuclear factor- $\kappa \mathrm{B}(\mathrm{NF}-\kappa \mathrm{B})$ [8], is responsible for the production of large amounts of NO in articular chondrocytes, both human and from other species [8-10]. Another NOS isoform, neuronal NOS (nNOS or NOS I), which produces lower amounts of NO, was found to be constitutively expressed in bovine chondrocytes and to be degraded in response to IL-1 [11]. The presence of a protein similar in size and antibody binding to nNOS, but with enzymatic activity characteristic of iNOS [12] has been reported in human OA chondrocytes. It is still unclear which NOS isoforms are expressed in normal and OA human chondrocytes.

Several lines of evidence indicate that NF- $\mathrm{KB}$ plays a crucial role in $\mathrm{OA}$, mediating important chondrocyte inflammatory responses that ultimately lead to cartilage destruction [13]. However, the mechanisms that regulate NF- $\mathrm{BB}$ activation, both in chondrocytes and other cells, are still incompletely understood. In particular, the question remains as to the role of NO on NF- $\kappa B$ activation and the subsequent expression of its target genes. In various cells from different species, NO has been shown to either induce [14$16]$ or inhibit $[11,17,18] \mathrm{NF}-\kappa \mathrm{B}$ activation in response to a variety 
of stimuli. These and similar studies led to the conclusion that the role of $\mathrm{NO}$ in modulating NF- $\kappa \mathrm{B}$ activation is cell-type specific and also depends on the experimental conditions. More recently, NO has been shown to be able to both up- and down-regulate NF- $\kappa B$ activity in murine macrophages, in a concentration- and timedependent manner [19]. In chondrocytes, either human or from other species, studies directly addressing this issue are scarce and the existing evidence, direct and indirect, points both to inhibitory $[11,20]$ and up-regulatory actions $[7,16]$.

Understanding the mechanisms that regulate NF- $\kappa \mathrm{B}$ activity in human chondrocytes, particularly the role of NO, will have important implications for the development of new therapeutic strategies for $\mathrm{OA}$ and other arthritic diseases. Furthermore, understanding how the NO found in OA joints is generated is also an important issue to define its role in the pathophysiology of the disease and will provide relevant information to determine the potential of therapeutically targeting the various NOS isoforms.

Aiming at contributing to elucidate these questions, this work focused first in identifying the NOS isoforms present in normal and OA human chondrocytes. Then, the basal NF- $\kappa \mathrm{B}$ activity was evaluated and compared with the pattern of expression of nNOS and iNOS to determine whether these parameters are correlated, either positive or negatively. To further elucidate the mechanisms that regulate NO production in human OA chondrocytes and possible repercussions in the regulation of NF- $\kappa B$ activity, the ability of cytokines and growth factors to modulate the levels of nNOS and iNOS was studied. Finally and to directly determine the ability of inducible NO to modulate NF- $\kappa \mathrm{B}$ activity, IL-1-induced NF- $\kappa \mathrm{B}$ activation was studied in the presence and absence of a general NOS inhibitor.

\section{Materials and methods}

\section{Cartilage samples}

Human OA cartilage was removed from the remaining of the distal femoral condyles obtained from patients (55-80 years old, mean $=67$ ) undergoing total knee replacement surgery at the Orthopedic Department of the University Hospital of Coimbra (HUC). All available cartilage was collected regardless of showing normal appearance or including damaged areas. Normal human knee cartilage was collected from the distal femoral condyles of multi-organ donors (17-54 years old, mean $=36$ ) within $24 \mathrm{~h}$ post-mortem, at the Tissue Bank of HUC. Cartilage from all multiorgan donors appeared normal without signs of fibrillation, rough surface, erosion or any other changes. All the procedures had the approval of the Ethics Committee of HUC.

\section{Isolation and cell culture}

Chondrocytes were isolated from the cartilage samples as described previously [21]. Briefly, cartilage slices underwent sequential digestion with protease K (Sigma Chemical Co., St. Louis, MO, USA) and collagenase (Roche, Indianapolis, IN, USA). To avoid chondrocyte dedifferentiation, non-proliferating monolayer cultures were setup by plating $2 \times 10^{6}$ chondrocytes/ml in Ham F-12 medium containing $3 \%$ antibiotic/antimycotic solution and $5 \%$ FBS and allowed to recover for $24 \mathrm{~h}$ at $37^{\circ} \mathrm{C}$ in a humidified atmosphere supplemented with $5 \% \mathrm{CO}_{2}$. Prior to any treatments, the cells were serum-starved overnight and thereafter maintained in culture medium with $1 \%$ antibiotic/antimycotic solution, without serum. Recombinant human IL-1 $\beta$ (Peprotech, Rocky Hill, NJ, USA) and/ or $N^{\mathrm{G}}$-Monomethyl-L-arginine acetate (L-NMMA) (Tocris Bioscience, Avonmouth, UK) were added to the cell cultures for the periods indicated in the figure legends.

\section{Measurement of NO production}

The basal NO production was measured as the amount of nitrite accumulated in the supernatants of $16 \mathrm{~h}$ chondrocyte cultures not submitted to any treatment. To evaluate the extent of inhibition of NO production by L-NMMA, the culture medium from the chondrocyte cultures treated with IL- 1 for $16 \mathrm{~h}$ was removed and replaced by new medium. The cells were incubated for $2 \mathrm{~h}$ with or without L-NMMA, followed by an additional 30 min incubation in the presence or absence of a second IL-1 stimulus. The culture medium was collected and the concentration of nitrite in the cell-free culture supernatants was measured using the spectrophotometric method based on the Griess reaction.

\section{Preparation of cytoplasmic and nuclear extracts}

The cells were lysed in $150 \mu$ of buffer 1 [10 mM Tris-HCl, $10 \mathrm{mM} \mathrm{NaCl}, 3 \mathrm{mM} \mathrm{MgCl} 2,0.5 \%$ Nonidet P-40, protease inhibitors (Complete Mini, Roche, Indianapolis, IN, USA), pH 7.5] and incubated on ice for $15 \mathrm{~min}$. The lysates were centrifuged at $2300 \mathrm{~g} /$ $5 \mathrm{~min}$ at $4{ }^{\circ} \mathrm{C}$ and the supernatants (cytoplasmic extracts) were stored at $-20^{\circ} \mathrm{C}$. The pellets were suspended in $25 \mu \mathrm{l}$ of buffer 2 [20 mM HEPES, $5 \mathrm{mM} \mathrm{MgCl}$, $0.2 \mathrm{mM}$ EDTA, $1 \mathrm{mM}$ DTT, $300 \mathrm{mM}$ $\mathrm{NaCl}, 20 \%$ glycerol, protease inhibitors (Complete Mini, Roche), $\mathrm{pH} 7.5$ ], incubated on ice for $20 \mathrm{~min}$ and centrifuged at $18,000 \mathrm{~g} /$ $20 \mathrm{~min}$ at $4{ }^{\circ} \mathrm{C}$. The supernatants (nuclear extracts) were stored at $-20^{\circ} \mathrm{C}$. The protein concentration was measured using the bicinchoninic acid/copper (II) sulfate protein assay kit (Sigma Chemical Co., St. Louis, MO, USA).

\section{Western blot analysis}

The cytoplasmic extracts were diluted in sodium dodecylsulfate (SDS) sample buffer (2.5\% SDS, $0.0625 \mathrm{M}$ Tris- $\mathrm{HCl}, 10 \%$ glycerol, 5\% 2-mercaptoethanol, 0.05\% bromophenol blue, $\mathrm{pH} 6.8$ ) and boiled for $5 \mathrm{~min}$ at $95^{\circ} \mathrm{C}$. Proteins $(25 \mu \mathrm{g})$ were separated by SDS/PAGE $[10 \%(v / v)]$ and transferred onto PVDF membranes by electroblotting. The membranes were blocked with $5 \%$ skim milk in Tris-buffered Saline-Tween (TBS-T, $20 \mathrm{mM}$ Tris- $\mathrm{HCl}, 150 \mathrm{Mm} \mathrm{NaCl}, 0.1 \%$ Tween 20) and then probed with antibodies against nNOS, iNOS (Abcam, Cambridge, UK) or IкB- $\alpha$ (Cell Signaling Technology, Inc., Danvers, MA, USA). After extensive washings with TBS-T, the blots were incubated with an alkaline phosphatase-conjugated secondary antibody. Immunoreactive complexes were detected by chemifluorescence using the ECF reagent (Amersham Biosciences, Buckinghamshire, UK). Fluorescence was detected with a Storm 840 fluorescence scanner (Amersham Biosciences). To ensure a roughly equal protein loading, mouse anti-actin monoclonal antibody (Chemicon International, Inc., Tremecula, CA, USA) was used as internal control. The intensity of the bands was analyzed using the ImageQuant ${ }^{\mathrm{TM}} \mathrm{TL}$ software from Amersham Biosciences.

\section{Electrophoretic mobility shift assay (EMSA)}

An oligonucleotide probe corresponding to the NF- $\kappa B$ consensus binding sequence (Santa Cruz Biotechnology, Santa Cruz, CA, USA) was end labeled with $\left[\gamma_{-}{ }^{32} \mathrm{P}\right]$-ATP by the T4 polynucleotide kinase (Amersham Pharmacia Biotech Inc., Piscatway, NJ, USA). Nuclear extracts $\left(10 \mu \mathrm{g}\right.$ of protein) were incubated for $40 \mathrm{~min}$ at $4{ }^{\circ} \mathrm{C}$ in $20 \mu \mathrm{l}$ binding reactions containing $100 \mathrm{mM}$ HEPES, pH 7.9, $5 \mathrm{mM}$ $\mathrm{MgCl}_{2}, 20 \%$ Ficoll 400, $2.5 \mathrm{mM}$ DTT, $250 \mathrm{mM} \mathrm{KCl}, 500 \mu \mathrm{g} / \mathrm{ml}$ PolidIdC, $5 \mathrm{mg} / \mathrm{ml} \mathrm{BSA}$, and $100,000 \mathrm{cpm} /$ reaction of $\left[\gamma_{-}{ }^{32} \mathrm{P}\right]$-labeled oligonucleotide probe. The DNA-protein complexes were resolved by electrophoresis in $7 \%$ native polyacrylamide gels in TBE $0.5 \times$ for $3 \mathrm{~h}$ at $150 \mathrm{~V}$, dried and visualized by autoradiography. The specific 
and non-specific complexes were analyzed with the ImageQuant ${ }^{\mathrm{TM}}$ TL software (Amersham Biosciences).

\section{Data analysis}

Where appropriate, statistical significance was assessed by the unpaired Student's $t$-test, performed using GraphPad Prism version 4.00 for Windows (GraphPad Software, San Diego, CA, USA, www.graphpad.com).

\section{Results}

\section{Expression of nNOS and iNOS in normal and OA chondrocytes}

To characterize the sources of NO in normal and OA articular chondrocytes, we evaluated the basal expression of nNOS and iNOS in the cytoplasmic extracts of chondrocytes isolated from 26 OA and from 6 normal cartilage samples. The supernatants of those chondrocyte cultures were used to evaluate the basal NO production. The relative level of each protein was calculated as the ratio between the intensity of its band and that of the respective actin band in the same membrane. The values obtained were plotted against the normal or OA status of each sample.

The dot-plot in Fig. 1A shows that nNOS is present, in variable amounts, in 17 (65.4\%) of the 26 OA extracts and in $5(83.3 \%)$ of the 6 normal samples analyzed. The protein detected by Western blot in normal and OA chondrocytes seems to be identical and present in either type of sample as a single band or as doublet or triplet bands. No specific band pattern could be ascribed to either normal or OA chondrocytes. Despite the wide variation in the amounts of nNOS found in distinct samples, either normal or OA, the mean value in OA samples is lower than that obtained in normal chondrocytes, indicating a tendency of OA chondrocytes to express lower levels of nNOS.

On the other hand, iNOS was spontaneously expressed, although in variable amounts, in 17 (65.4\%) of the 26 OA samples, but in only 2 (33.3\%) of the 6 normal samples analyzed (Fig. 1B). Interestingly, these two samples were obtained from the older donors, aged 48 and 54 years old. Although the cartilage from those 2 donors did not show evident macroscopic signs of arthritic lesions, the possibility that OA was already in progress, especially at the cellular and molecular levels, cannot be ruled out and may account for the observed iNOS expression. Accordingly, iNOS was absent in the remaining normal cartilage samples obtained from younger donors, below the age of 40 years old.

Taken together, the results in Fig. 1 show that approximately $46 \%$ (12 out of 26 ) of the OA samples analyzed expressed both NOS isoforms, almost 39\% (10 out of 26) expressed either nNOS (5 out of 26) or iNOS (5 out of 26 ) and 15\% (4 out of 26 ) were negative for both isoforms. Furthermore, the dot-plots in Fig. 1 also show a tendency of OA chondrocytes to express higher levels of iNOS and lower levels of nNOS, relatively to normal chondrocytes.

The results obtained clearly distinguished nNOS from iNOS, both in normal and OA chondrocytes. Nevertheless and to further confirm the specificity of the antibodies used, the membranes initially probed with the anti-nNOS antibody were stripped and reprobed with the anti-iNOS antibody which did not reveal any band in the lane corresponding to the positive control for nNOS (data not shown). Moreover, the pattern of nNOS expression in the samples analyzed, either normal or OA, does not overlap with that relative to iNOS expression. Actually, several samples, both normal and $\mathrm{OA}$, that express one of the isoforms, do not express the other one, further confirming the specificity of the antibodies used.

Significantly different concentrations of nitrite were found in the supernatants of normal and OA chondrocytes cultures, depending on whether iNOS was expressed. The average nitrite concentration in the culture medium from normal or OA chondrocytes that did not express iNOS was $3.6 \pm 1.0 \mu \mathrm{M}$, whereas in cells expressing iNOS it was $9.4 \pm 2.9 \mu \mathrm{M}(P<0.01)$. Regardless of whether iNOS was spontaneously expressed or not, treatment with IL-1, $20 \mathrm{ng} /$ $\mathrm{ml}$, for $16 \mathrm{~h}$ increased NO production to $24.6 \pm 5.4 \mu \mathrm{M}$. Therefore,
A
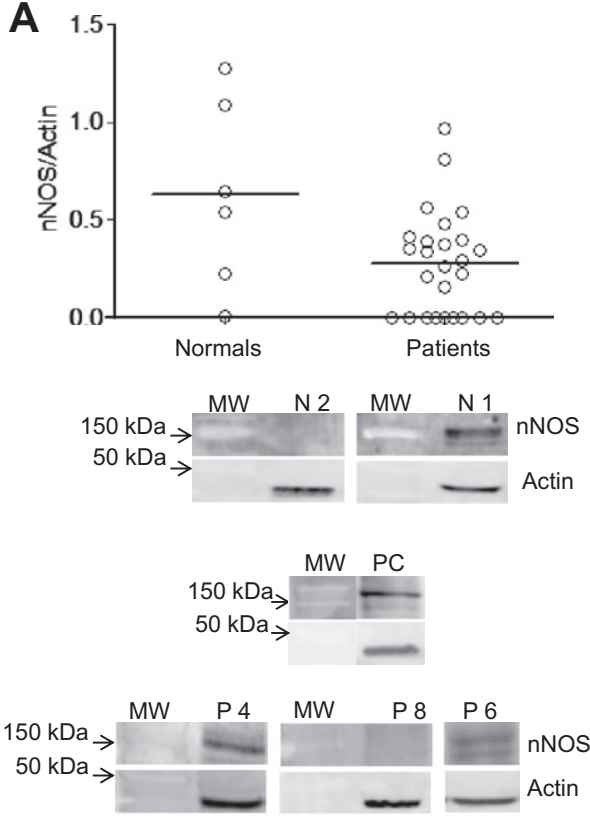

B
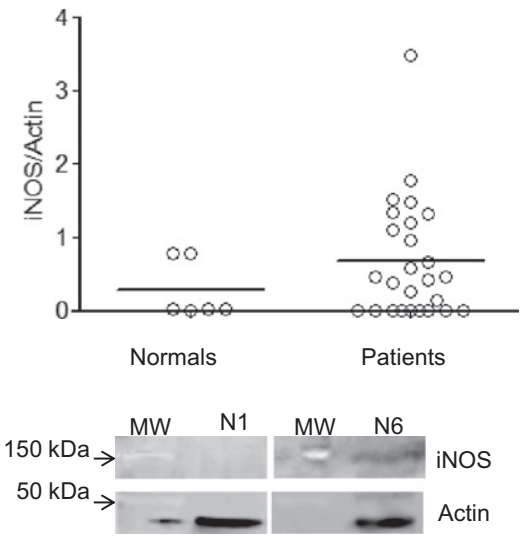

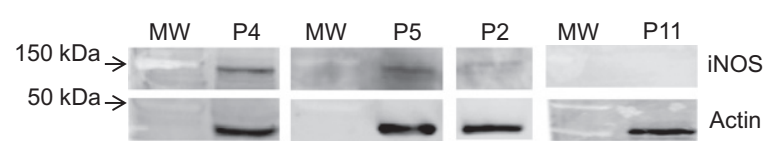

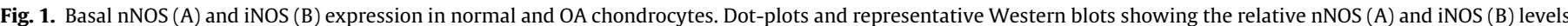

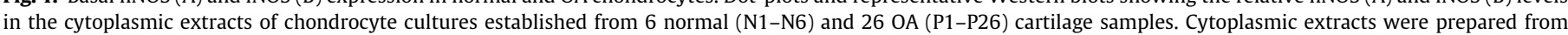

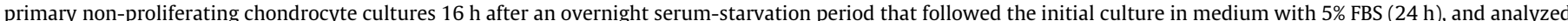

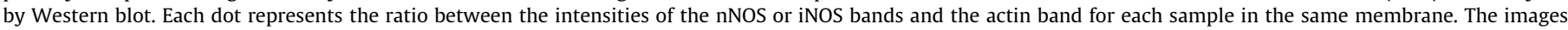
shown are representative of samples, either normal or OA, positive or negative for nNOS and iNOS. MW, molecular weight marker; PC, positive control. 
NO production in chondrocytes spontaneously expressing iNOS was significantly lower than that obtained upon stimulation with IL-1, indicating that iNOS expression and activity in OA chondrocytes is sub-maximal.

\section{$N F-\kappa B$ activity in normal and $O A$ chondrocytes}

Fig. 2 shows the presence of variable amounts of IкB- $\alpha$ in the majority (88.5\%) of the cytoplasmic extracts from OA chondrocytes and in all the normal samples. Nevertheless, the mean relative levels of IKB- $\alpha$ are lower in OA than in normal chondrocytes, although a trend cannot clearly be drawn from the dot-plot shown in Fig. 2 .

Since I $\kappa B-\alpha$ was present in the majority of the OA samples, NF$\kappa B-D N A$ binding activity was assessed to determine, more specifically, the basal NF- $\kappa B$ activation status. For this purpose, EMSA results were obtained in $12 \mathrm{OA}$ and 5 normal samples. A small but detectable NF- $\mathrm{KB}-\mathrm{DNA}$ binding activity was present in the nuclear extracts from all the normal chondrocyte cultures analyzed. Therefore, NF- $\kappa \mathrm{B}-\mathrm{DNA}$ binding activity was considered to be increased in the nuclear extracts from OA chondrocytes only when the intensity of the corresponding complexes was higher than that observed in the normal extracts analyzed in the same gel. Analysis of the specific NF- $\kappa B-D N A$ complexes showed increased NF- $\kappa B$ activity in approximately $90 \%$ ( 11 out of 12 samples) of the nuclear extracts from OA chondrocytes. Furthermore, the average intensity of the complexes detected in those 11 OA samples (1.82 \pm 0.23$)$ is significantly higher than the intensity of the complexes detected in the normal samples $(0.91 \pm 0.05)$ (Fig. $3 \mathrm{~A})$. Fig. 3B shows EMSA autoradiographies representative of the NF- $\kappa B$ activation status in normal and OA chondrocytes.

Comparison of the NF- $\kappa \mathrm{B}$ activation status with the presence or absence of the NOS isoforms shows increased activity of this transcription factor in all the nuclear extracts from OA chondrocytes that also express iNOS $(n=9)$, either alone $(n=3)$ or in conjunction
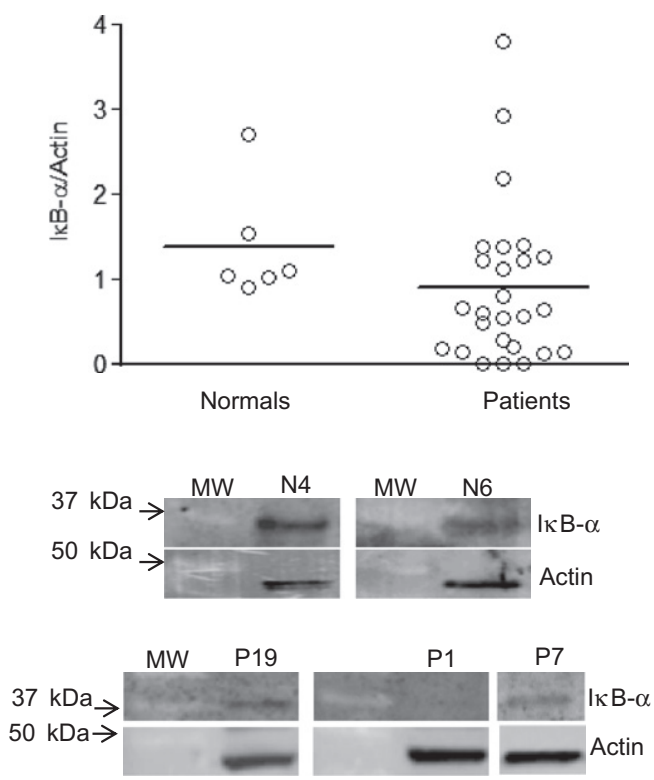

Fig. 2. Basal $\mathrm{I} \kappa \mathrm{B}-\alpha$ expression in normal and $\mathrm{OA}$ chondrocytes. Dot-plot and representative Western blots showing the relative I $\kappa \mathrm{B}-\alpha$ levels in the cytoplasmic extracts of chondrocyte cultures established from 6 normal (N1-N6) and 26 OA (P1-P26) cartilage samples. Cytoplasmic extracts were prepared from primary nonproliferating chondrocyte cultures $16 \mathrm{~h}$ after an overnight serum-starvation period that followed the initial culture in medium with 5\% FBS $(24 \mathrm{~h})$, and analyzed by Western blot. Each dot represents the ratio between the intensities of the IкB- $\alpha$ and the actin bands for each sample in the same membrane. The images shown are representative of samples, either normal or OA, positive or negative for I $\mathrm{I} B-\alpha$. MW molecular weight marker.
A

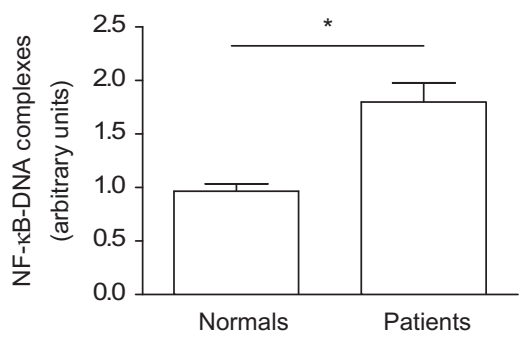

B

Free

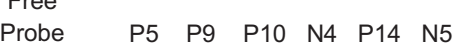
complexes

Non-specific complexes >

Free Oligo.>

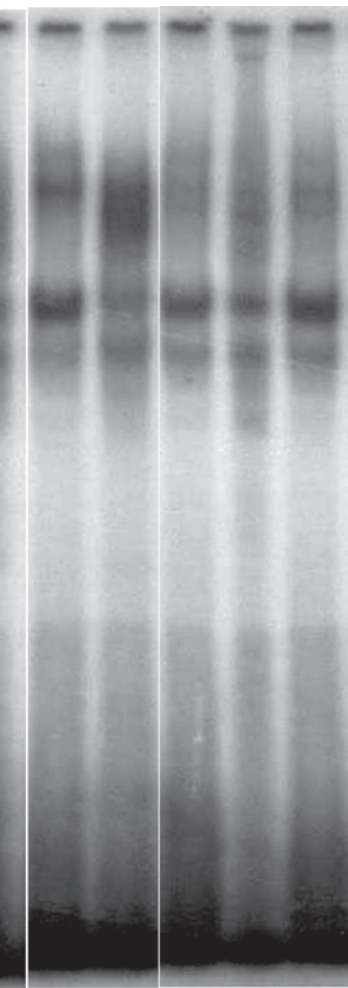

Fig. 3. Basal NF- $\kappa B$ activity in normal and $O A$ chondrocytes. Nuclear extracts were prepared from primary non-proliferating chondrocyte cultures $16 \mathrm{~h}$ after an overnight serum-starvation period that followed the initial culture in medium with $5 \%$ FBS $(24 \mathrm{~h})$. (A) The intensity of the specific NF- $\mathrm{KB}-\mathrm{DNA}$ complexes in normal and OA nuclear extracts was normalized to that of the corresponding nonspecific complexes. The bars represent means \pm SEM of the results obtained with the nuclear extracts from 5 normal and 12 OA samples, respectively. ${ }^{*} P<0.05$. (B) Representative autoradiography of the results depicted in A.

with nNOS $(n=6)$. Increased NF- $\mathrm{BB}-\mathrm{DNA}$ complexes were also found in the nuclear extract from one sample in which both NOS isoforms were absent and in another one that lacked iNOS, but not nNOS. The only sample in which NF- $\kappa B$ activity was not increased, expressed nNOS but not iNOS.

Interestingly, I $\mathrm{B}-\alpha$ was detected in the majority of the OA samples analyzed, including those that showed increased NF- $\mathrm{KB}-\mathrm{DNA}$ binding activity.

\section{Modulation of $n N O S$ and iNOS protein levels by $I L-1 \beta$}

To further elucidate the mechanisms that regulate NO production in human OA chondrocytes and possible repercussions in the modulation of NF- $\kappa \mathrm{B}$ activity, nNOS and iNOS levels were evaluated in the cytoplasmic extracts of OA chondrocyte cultures treated with the pro-inflammatory and catabolic cytokines, IL-1 
$(20 \mathrm{ng} / \mathrm{ml})$ and tumor necrosis factor- $\alpha$ (TNF- $\alpha, 20 \mathrm{ng} / \mathrm{ml})$, and with the anabolic growth factors, insulin-like growth factor-1 $(\mathrm{IGF}-1,100 \mathrm{ng} / \mathrm{ml})$, and transforming growth factor- $\beta$ (TGF- $\beta$, $10 \mathrm{ng} / \mathrm{ml}$ ), for various periods of time.

Fig. 4 shows significantly decreased levels of nNOS in OA cells treated with IL-1 for $16 \mathrm{~h}(55.1 \pm 7.3 \%)$, relatively to control untreated cells, whereas treatment for shorter periods (5 or $30 \mathrm{~min})$ had no effect $(97.4 \pm 3.4 \%$ and $104.9 \pm 12.3 \%$, respectively). Treatment with TNF- $\alpha$ also induced nNOS disappearance (data not shown). Neither IL-1 nor TNF- $\alpha$ was capable of inducing nNOS synthesis for up to $48 \mathrm{~h}$ treatment (data not shown).

iNOS protein levels in OA chondrocytes decreased to $45.4 \pm 10.6 \%$ of the control upon treatment with IL- 1 for only $15 \mathrm{~min}$, and were further reduced to $41.5 \pm 3.3 \%$ when the treatment period was extended to $2 \mathrm{~h}$ (Fig. 5B.1). On the other hand, treatment with this cytokine for $16 \mathrm{~h}$ significantly increased iNOS levels to $429.4 \pm 74.6 \%$ of the control. Furthermore, in OA chondrocyte cultures that did not express iNOS spontaneously, treatment with IL-1 for $16 \mathrm{~h}$ was also effective in inducing its expression (Fig. 5B.2), indicating that its absence, in untreated cells, is not due to a permanent inhibition of its expression or induction of its degradation. Moreover, treatment of the chondrocyte cultures with TNF- $\alpha$ induced iNOS disappearance and synthesis in the same manner as IL-1 (data not shown).

On the other hand, treatment with IGF-1 or TGF- $\beta$, for up to $48 \mathrm{~h}$, had no effect on the levels of either nNOS or iNOS, regardless of their presence or absence in basal conditions (data not shown).

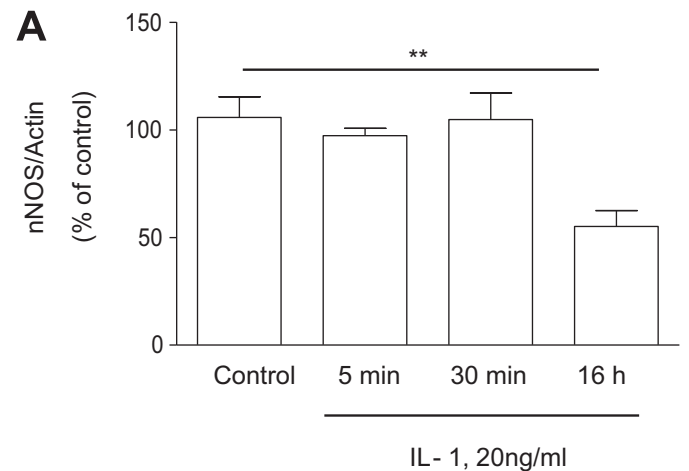

B

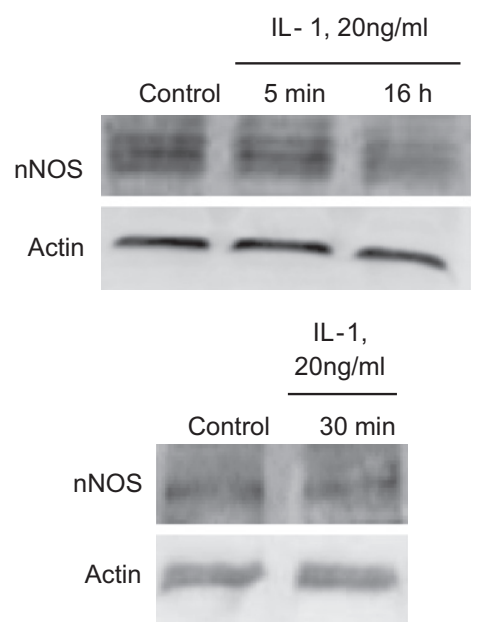

Fig. 4. nNOS levels in the cytoplasmic extracts from OA chondrocyte cultures treated with IL-1, $20 \mathrm{ng} / \mathrm{ml}$, for the periods indicated. (A) Each bar represents the intensity (in percentage relative to the control) of the bands corresponding to nNOS normalized to the respective actin band. The results shown are means \pm SEM of, at least, three independent experiments. ${ }^{*} P<0.05$. (B) The images shown are representative of the results obtained with, at least, three distinct OA cartilage samples for each treatment period.

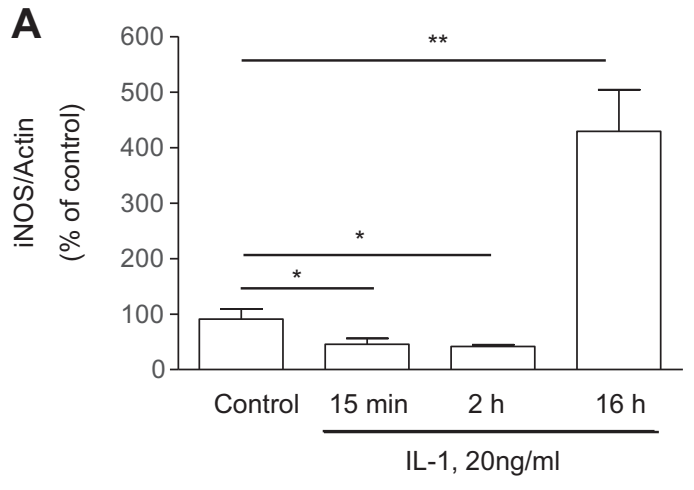

B.1

IL-1, 20ng/ml

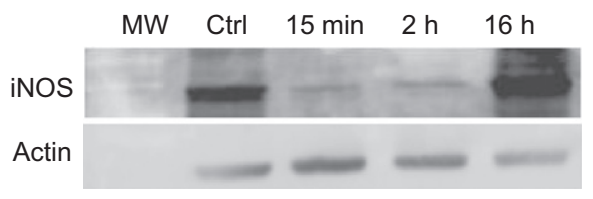

B.2

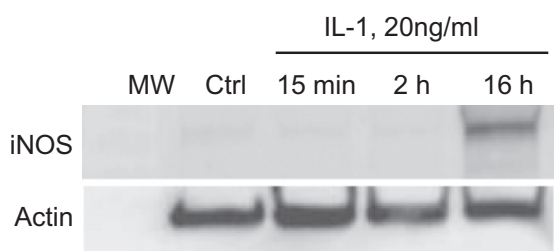

Fig. 5. iNOS levels in the cytoplasmic extracts from OA chondrocyte cultures treated with IL-1, $20 \mathrm{ng} / \mathrm{ml}$, for the periods indicated. (A) Each bar represents the intensity (in percentage relative to the control) of the bands corresponding to iNOS normalized to the respective actin band. The results shown are means \pm SEM of three independent experiments. ${ }^{*} P<0.05$ and ${ }^{* *} P<0.01$. (B) The images shown are representative of the responses to IL-1 of OA chondrocyte cultures that did (B.1) or did not (B.2) express iNOS spontaneously.

\section{Role of endogenous inducible NO on IL-1-induced NF- $\kappa \mathrm{B}$ activation}

To more directly elucidate whether NO, produced endogenously by iNOS, can modulate NF- $\kappa B$ activation, chondrocyte cultures were treated with IL-1, $20 \mathrm{ng} / \mathrm{ml}$, for $16 \mathrm{~h}$ to induce iNOS expression and the subsequent NO production. Then, the cells were incubated for $2 \mathrm{~h}$ in the presence or absence of L-NMMA, a general NOS inhibitor, followed by an additional 30 min incubation in the presence or absence of a second IL-1 stimulus ( $20 \mathrm{ng} / \mathrm{ml}$ ) to induce NF$\kappa \mathrm{B}$ activation. Measurement of the nitrite concentration in the culture supernatants confirmed that treatment with L-NMMA, $250 \mu \mathrm{M}$, reduced IL-1-induced NO production by approximately $50 \%$ (data not shown) relatively to the cells treated with IL-1 for $16 \mathrm{~h}$ and thereafter left untreated.

I $\kappa$ B- $\alpha$ levels in cells treated only with the first IL- 1 stimulus were identical to those detected in untreated cells (Fig. 6A). As expected, treatment with IL-1 for $30 \mathrm{~min}$, in the absence of L-NMMA, reduced I $\mathrm{KB}-\alpha$ levels to $65.0 \pm 3.5 \%$ of those found in cells treated only with the first IL-1 stimulus, indicating that NF- $\kappa B$ had been activated (Fig. 6A). On the other hand, in cells treated with LNMMA, but not with the second IL- 1 stimulus, IКB- $\alpha$ levels decreased to $56.0 \pm 3.4 \%$. No significant difference was found between I $\kappa \mathrm{B}-\alpha$ levels in cells treated only with the second IL-1 stimulus or with L-NMMA alone. Addition of the second IL-1 stimulus to chondrocyte cultures in the presence of L-NMMA further reduced I $\mathrm{KB}-\alpha$ levels to $42.5 \pm 2.9 \%$ (Fig. 6A), indicating that the presence of the NOS inhibitor facilitated IL-1-induced I $\mathrm{B}$ - $\alpha$ degradation. 
A
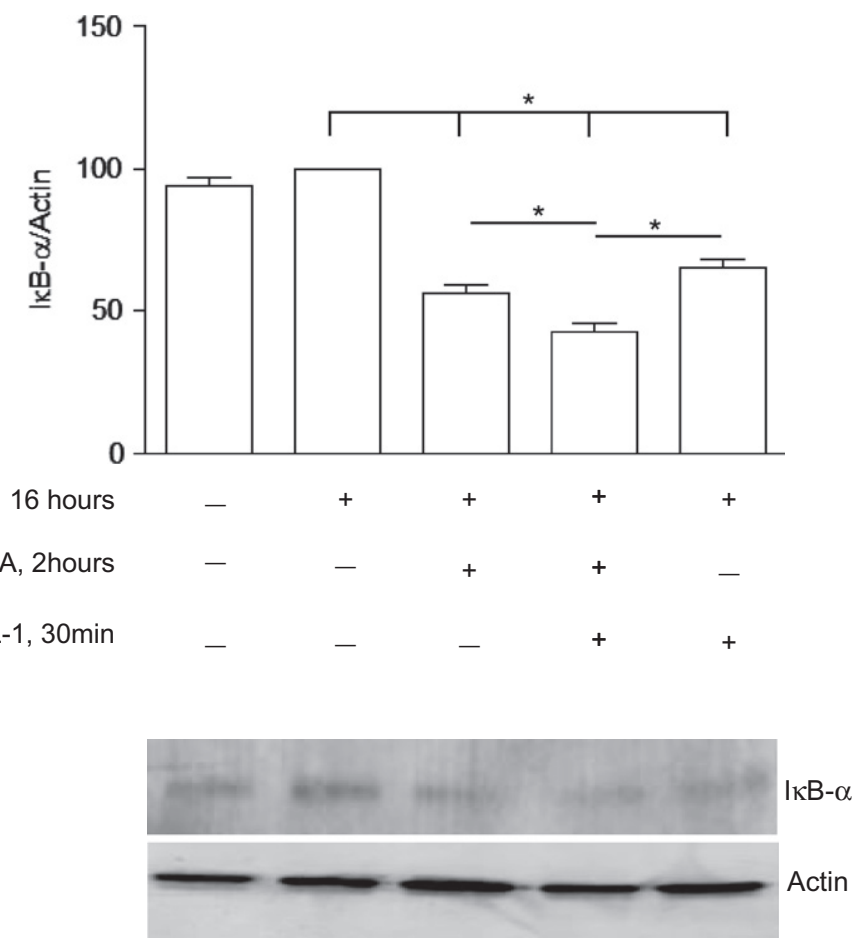

B

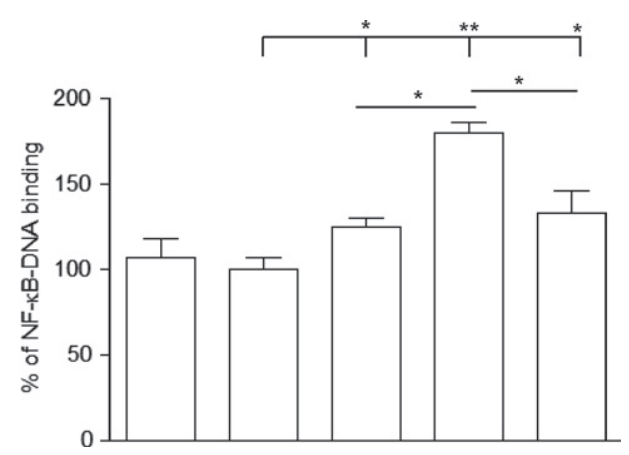

\section{Specific NF-кB-DNA, complexes \\ Non-specific complexes $^{>}$}

Free Oligo. >

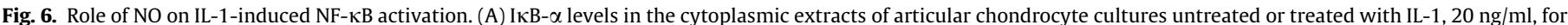

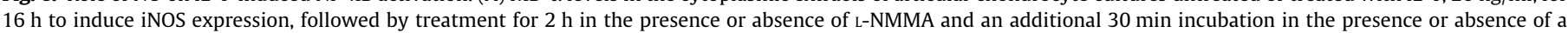

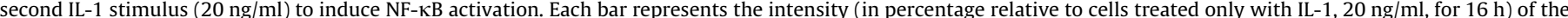

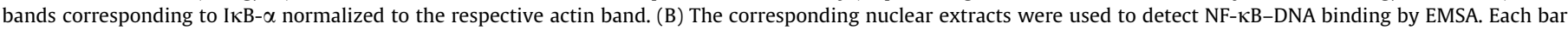

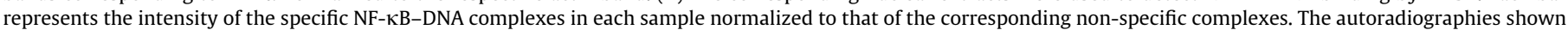

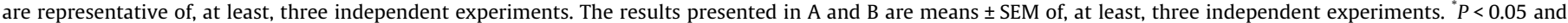
${ }^{* *} P<0.01$.

These results were further confirmed by EMSA of the corresponding nuclear extracts. Fig. $6 \mathrm{~B}$ shows that the intensity of the specific NF- $\kappa B-D N A$ complexes is identical in untreated cells and in those treated only with the first IL-1 stimulus, but increased significantly in cells treated with the second IL-1 stimulus in the absence of L-NMMA $(133.3 \pm 12.3 \%)$. The intensity of the specific NF$\kappa \mathrm{B}-\mathrm{DNA}$ complexes was further increased in cells treated with the second IL-1 stimulus in the presence of that inhibitor
(179.7 $\pm 6.4 \%$ ). Furthermore, treatment with L-NMMA alone was sufficient to increase the intensity of the specific NF- $\kappa B-D N A$ complexes by approximately $25 \%$ relatively to the cells treated only with the first IL-1 stimulus.

Taken together, the results in Fig. 6 show increased IКB- $\alpha$ degradation and NF- $\kappa \mathrm{B}-\mathrm{DNA}$ binding activity in cells treated with IL-1 in the presence of L-NMMA, suggesting that lower NO levels facilitate NF- $\kappa \mathrm{B}$ activation, or conversely, that the 
presence of NO contributes to limit the activation of this transcription factor.

\section{Discussion}

The results obtained (Fig. 1) show that normal and OA chondrocytes differentially express nNOS and iNOS, the first being more frequently present in normal chondrocytes, whereas iNOS prevailed in OA chondrocytes. These results suggest that normal human articular chondrocytes constitutively express nNOS, which is in agreement with our previous studies in bovine chondrocytes [11], but in contrast with those reported by Amin and co-workers [12] who found a NOS protein similar to nNOS only in OA chondrocytes. However, the protein identified in the later study produced large amounts of NO, which is a distinctive feature of iNOS, and it is not clear whether that protein is identical to nNOS, a modification of iNOS, or even a novel NOS isoenzyme [22]. On the other hand, in our study, one or two bands with apparent molecular weights lower than that characteristic of nNOS and that reacted with the anti-nNOS antibody were detected in some samples, both normal and OA. Those bands may represent partially degraded forms of the typical nNOS enzyme or may correspond to different nNOS protein isoforms resulting from alternative mRNA splicing. These are, in fact, two major forms of post-transcriptional regulation of nNOS, although the determinants or mechanisms that regulate those events and their biological significance are yet poorly understood [23]. Further studies are required to fully characterize, at the molecular level, the bands detected and to assess their biological significance.

Although the present study did not intend to be quantitative, but rather to detect the presence or absence of the two NOS isoforms, the dot-plots in Fig. 1 clearly show that the amount of each of these proteins present in different samples is highly variable. This variability suggests that the mechanisms regulating nNOS and iNOS in articular chondrocytes differ considerably between OA patients, possibly reflecting differences in the evolution of the disease process. In fact, even though all the patients had advanced $\mathrm{OA}$, with extensive erosion demanding total knee replacement surgery, the cartilage still remaining showed marked macroscopic differences (for instance, in stiffness or tenderness) between patients, suggesting that the evolution of the disease process is not uniform among patients.

The results obtained in this study show increased NF- $\kappa B$ activity in samples that also expressed iNOS (Fig. 3). Thus, a tempting explanation would be that the NO being produced would sustain NF- $\kappa B$ activation. However, we also found increased NF- $\kappa B$ activity in chondrocytes that did not express iNOS or even nNOS. Furthermore, Fig. 6 shows that even a partial reduction of the endogenous inducible NO production is sufficient to induce I $\kappa \mathrm{B}-\alpha$ degradation and NF- $\kappa \mathrm{B}-\mathrm{DNA}$ binding activity and to potenciate the effects of IL-1. These results are in agreement with our previous studies in bovine chondrocytes in which addition of a NO donor to the cell cultures decreased IL-1-induced NF- $\mathrm{BB}$ activity and iNOS expression [11].

However, another study in which bovine chondrocytes were used, showed that NO is required to sustain lipopolysaccharide and cytokine-induced NF- $\kappa B$ activation [16]. Since bovine chondrocytes constitutively express nNOS, but not iNOS [11], and LNMMA was added concomitantly or shortly after the LPS and cytokine mixture, the effects reported in that study can only be attributed to inhibition of nNOS activity, implying that constitutive NO or low concentrations of NO have an up-regulatory effect on NF$\kappa \mathrm{B}$ activity. In the current study, L-NMMA was added to the chondrocyte cultures after induction of iNOS expression, and as such it evaluated mainly the contribution of inducible NO or high concen- trations of NO, indicating that high levels of NO restrain NF- $\mathrm{NB}$ activation. Taken together, these studies suggest that high and low NO concentrations exert opposite effects on NF- $\kappa \mathrm{B}$ activation in chondrocytes. This is in agreement with a study in murine macrophages that first reported the dual effect of NO on NF- $\kappa \mathrm{B}$ activation, showing that small amounts of NO, as those produced by the constitutive NOS isoforms, facilitated and high concentrations, resulting from iNOS activity, inhibited NF- KB activation [19]. However, significant differences may exist between bovine and human chondrocytes. In fact, we found that IL-1-induced nNOS degradation occurs more rapidly in bovine chondrocytes [11] than in human cells (Fig. 4), which may contribute to species differences as to the role of constitutive NO in modulating NF- $\kappa \mathrm{B}$ activation in chondrocytes.

One possible mechanism contributing to the dual role of NO on $\mathrm{NF}-\kappa \mathrm{B}$ activation is the intracellular redox potential of the cells, since it determines the type of redox-end products of NO that can be generated in a given moment or in certain conditions [24]. Indeed, the two major redox derivatives of NO, peroxynitrite and $S$-nitrosothiol, have been shown to exert opposite effects on NF- $\kappa B$ activation [15,25]. More recently, other mechanisms by which NO can modulate, negative or positively, NF- $\kappa B$ activity have been identified [26,27], but their relevance in different cells and under distinct conditions and stimuli remains to be elucidated.

On the other hand, the expression and regulation of the constitutive and inducible NOS isoforms are crucial determinants of time-dependent changes in NO concentration and thus on NF- $\kappa B$ activity. Pro-inflammatory stimuli were proposed to generate those time-dependent changes by promoting the differential expression of the constitutive and inducible NOS isoforms [19]. The ability of IL-1 to induce the disappearance of both nNOS and iNOS found in the present study (Figs. 4 and 5) is in agreement with this hypothesis.

Studies in other cells demonstrated that degradation is an important mechanism whereby both nNOS and iNOS are regulated $[28,29]$. The current study indicates that degradation is also involved in the regulation of nNOS and iNOS in human chondrocytes and probably contributes to the variable amounts of these enzymes found among OA chondrocytes. Since iNOS expression is induced by inflammatory cytokines, like IL-1, its concentration in chondrocytes, at any given moment, probably results from the balance between the rates of synthesis and degradation, determined, at least in part, by the availability of cytokines. On the other hand, nNOS regulation by cytokines seems to depend mainly on its degradation, since neither IL-1 nor TNF- $\alpha$ was capable of inducing its synthesis, but both cytokines induced its degradation (Fig. 4 and data not shown). Furthermore, since the anabolic growth factors, IGF- 1 and TGF- $\beta$, had no effect on the levels of either nNOS or iNOS (data not shown), at least in the conditions tested, it seems that pro-inflammatory cytokines are the major regulators of NOS isoforms in human chondrocytes.

In terms of NO production, the consequence of this process is that the action of pro-inflammatory cytokines, like IL- 1 or TNF- $\alpha$, in chondrocytes can lead, in the short term, to a low NO production due to the activity of the eventually existing nNOS, since iNOS, even if previously expressed, rapidly disappears. Thus, the low NO levels, produced by nNOS, can favor or, at least, not affect, $\mathrm{NF}-\kappa \mathrm{B}$ activation and the subsequent expression of iNOS and other NF- $\kappa B$-dependent genes. Newly synthesized iNOS then leads to an increased NO production which can terminate NF- $\kappa B$ activation until a new stimulus restarts the process.

Considering the osteoarthritic joint, this suggests that a dynamic equilibrium can be established in which the levels of NO and pro-inflammatory cytokines are mutually regulated, contributing to sustain over time, a low to moderate level of NF- $\kappa B$ activity

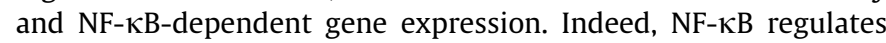


the expression of many of the major pro-inflammatory cytokines found in the OA joint, like IL-1, TNF- $\alpha$ and IL-18, which in turn, induce its activation [30,31]. In the absence of regulatory mechanisms, this might lead to a positive feed-back process in which high NF- $\kappa \mathrm{B}$ activity and expression of pro-inflammatory genes, including iNOS and pro-inflammatory cytokines, were maintained. Instead, OA is characterized by a low grade inflammation [32] in which the cytokine and nitrite levels (reflecting NO production) in the joint are much lower than those found in inflammatory types of arthritis [33,34]. This suggests that, in OA, NF- $\kappa B$ is not fully activated, but rather maintained in a state of moderate activity. The presence of detectable amounts of the NF- $\kappa B$ inhibitor, I $\kappa \mathrm{B}-\alpha$, in the cytoplasmic extracts of the majority of the OA samples analyzed (Fig. 2), including those that showed increased NF$\kappa \mathrm{B}$ activity (Fig. 3 ), and the moderate NO production, even in chondrocytes that expressed iNOS, further support this hypothesis. The observed inhibitory effect of iNOS-derived NO on IL-1-induced NF$\kappa \mathrm{B}$ activity (Fig. 6 ) together with the cytokine-induced degradation of nNOS and iNOS provide a mechanism by which pro-inflammatory cytokines and NF- $\kappa \mathrm{B}$ can be sustained in a state of moderate activity, contributing to the perpetuation of the low grade inflammation characteristic of $\mathrm{OA}$, but preventing the occurrence of an exacerbated inflammatory response.

In summary, this study shows that OA chondrocytes, relatively to normal cells, tend to express iNOS and less frequently nNOS and to present moderate spontaneous NF- $\kappa \mathrm{B}$ activity, which seems to be regulated, at least in part, by the balanced production of NO resulting from a dynamic process that, at any given moment, determines the availability of the constitutive and inducible NOS isoforms. The findings presented favor an inhibitory role of high amounts of NO on NF- $\kappa \mathrm{B}$ activity in chondrocytes and reconcile observations, so far, apparently contradictory [11,16]. Moreover, the down-regulatory role of NO on NF- $\kappa \mathrm{B}$ activation warrants caution as to the possible utilization of NOS inhibitors in the therapy of OA.

\section{Acknowledgments}

The authors wish to thank Dr. Maria Teresa Cruz, professor at the Faculty of Pharmacy and researcher at the Center for Neurosciences and Cell Biology, University of Coimbra, Portugal, for the critical review of this manuscript. Rosa S.C. is supported by a Ph.D. fellowship (SFRH/BD/19763/2004) from the Portuguese Foundation for Science and Technology (FCT). This work was supported by Grant PTDC/SAU-OSM/67936/2006 from FCT.

\section{References}

[1] T. Aigner, J. Haag, J. Martin, J. Buckwalter, Osteoarthritis: aging of matrix and cells-going for a remedy, Curr. Drug Targets 8 (2007) 325-331.

[2] M.B. Goldring, Update on the biology of the chondrocyte and new approaches to treating cartilage diseases, Best Practice Res. Clin. Rheumatol. 20 (2006) $1003-1025$.

[3] J.A. Buckwalter, J.A. Martin, Osteoarthritis, Adv. Drug Delivery Rev. 58 (2006) 150-167.

[4] H.J. Hauselmann, L. Oppliger, B.A. Michel, M. Stefanovic-Racic, C.H. Evans, Nitric oxide and proteoglycan biosynthesis by human articular chondrocytes in alginate culture, FEBS Lett. 352 (1994) 361-364.

[5] Y.Y. Lo, J.A. Conquer, S. Grinstein, T.F. Cruz, Interleukin-1 $\beta$ induction of c-fos and collagenase expression in articular chondrocytes: involvement of reactive oxygen species, J. Cell Biochem. 69 (1998) 19-29.

[6] F.J. Blanco, R.L. Ochs, H. Schwarz, M. Lotz, Chondrocyte apoptosis induced by nitric oxide, Am. J. Pathol. 146 (1995) 75-85.

[7] F.J. Blanco, M. Lotz,IL-1-induced nitric oxide inhibits chondrocyte proliferation via PGE2, Exp. Cell Res. 218 (1995) 319-325.
[8] A.F. Mendes, M.M. Caramona, A.P. Carvalho, M.C. Lopes, Role of mitogenactivated protein kinases and tyrosine kinases on IL-1-induced NF- $\kappa \mathrm{B}$ activation and iNOS expression in bovine articular chondrocytes, Nitric Oxide 6 (2002) 35-44.

[9] R.M. Palmer, M.S. Hickery, I.G. Charles, S. Moncada, M.T. Bayliss, Induction of nitric oxide synthase in human chondrocytes, Biochem. Biophys. Res. Commun. 193 (1993) 398-405.

[10] J. Stadler, M. Stefanovic-Racic, T.R. Billiar, R.D. Curran, L.A. McIntyre, H.I. Georgescu, R.L. Simmons, C.H. Evans, Articular chondrocytes synthesize nitric oxide in response to cytokines and lipopolysaccharide, J. Immunol. 147 (1991) 3915-3920.

[11] A.F. Mendes, A.P. Carvalho, M.M. Caramona, M.C. Lopes, Role of nitric oxide in the activation of NF- $\mathrm{KB}, \mathrm{AP}-1$ and NOS II expression in articular chondrocytes, Inflamm. Res. 51 (2002) 369-375.

[12] A.R. Amin, P.E. Di Cesare, P. Vyas, M. Attur, E. Tzeng, T.R. Billiar, S.A. Stuchin, S.B. Abramson, The expression and regulation of nitric oxide synthase in human osteoarthritis-affected chondrocytes: evidence for up-regulated neuronal nitric oxide synthase, J. Exp. Med. 182 (1995) 2097-2102.

[13] J.A. Roman-Blas, S.A. Jimenez, NF- $\kappa B$ as a potential therapeutic target in osteoarthritis and rheumatoid arthritis, Osteoarthritis Cartilage 14 (2006) 839-848.

[14] H. Muhl, J. Pfeilschifter, Amplification of nitric oxide synthase expression by nitric oxide in interleukin $1 \beta$-stimulated rat mesangial cells, J. Clin. Invest. 95 (1995) 1941-1946.

[15] C. Zouki, L. Jozsef, S. Ouellet, Y. Paquette, J.G. Filep, Peroxynitrite mediates cytokine-induced IL-8 gene expression and production by human leukocytes, J. Leukoc. Biol. 69 (2001) 815-824.

[16] R.M. Clancy, P.F. Gomez, S.B. Abramson, Nitric oxide sustains nuclear factor $\kappa B$ activation in cytokine-stimulated chondrocytes, Osteoarthritis Cartilage 12 (2004) 552-558.

[17] M. Colasanti, T. Persichini, M. Menegazzi, S. Mariotto, E. Giordano, C.M. Caldarera, V. Sogos, G.M. Lauro, H. Suzuki, Induction of nitric oxide synthase mRNA expression. Suppression by exogenous nitric oxide, J. Biol. Chem. 270 (1995) 26731-26733.

[18] S.K. Park, H.L. Lin, S. Murphy, Nitric oxide regulates nitric oxide synthase-2 gene expression by inhibiting NF- $\kappa \mathrm{B}$ binding to DNA, Biochem. J. 322 (1997) 609-613.

[19] L. Connelly, M. Palacios-Callender, C. Ameixa, S. Moncada, A.J. Hobbs, Biphasic regulation of NF- $\kappa$ B activity underlies the pro- and anti-inflammatory actions of nitric oxide, J. Immunol. 166 (2001) 3873-3881.

[20] Y.E. Henrotin, S.X. Zheng, G.P. Deby, A.H. Labasse, J.M. Crielaard, J.Y. Reginster, Nitric oxide downregulates interleukin $1 \beta$ (IL-1 $\beta$ ) stimulated IL-6, IL-8, and prostaglandin E2 production by human chondrocytes, J. Rheumatol. 25 (1998) 1595-1601.

[21] T.F. Cruz, G. Mills, K.P.H. Pritzker, R.A. Kandel, Inverse correlation between tyrosine phosphorylation and collagenase production in chondrocytes, Biochem. J. 269 (1990) 717-721.

[22] K. Vuolteenaho, T. Moilanen, N. Al-Saffar, R.G. Knowles, E. Moilanen, Regulation of the nitric oxide production resulting from the glucocorticoidinsensitive expression of iNOS in human osteoarthritic cartilage, Osteoarthritis Cartilage 9 (2001) 597-605.

[23] W.K. Alderton, C.E. Cooper, R.G. Knowles, Nitric oxide synthases: structure, function and inhibition, Biochem. J. 357 (2001) 593-615.

[24] R.M. Clancy, A.R. Amin, S.B. Abramson, The role of nitric oxide in inflammation and immunity, Arthritis Rheum 41 (1998) 1141-1151.

[25] H.E. Marshall, J.S. Stamler, Inhibition of NF- $\kappa B$ by $S$-nitrosylation, Biochemistry 40 (2001) 1688-1693.

[26] S. Mariotto, Y. Suzuki, T. Persichini, M. Colasanti, H. Suzuki, O. Cantoni, Crosstalk between NO and arachidonic acid in inflammation, Curr. Med. Chem. 14 (2007) 1940-1944.

[27] V.A. Yakovlev, I.J. Barani, C.S. Rabender, S.M. Black, J.K. Leach, P.R. Graves, G.E. Kellogg, R.B. Mikkelsen, Tyrosine nitration of IкB- $\alpha$ : a novel mechanism for NF- $\kappa$ B activation, Biochemistry 46 (2007) 11671-11683.

[28] P.J. Kolodziejski, A. Musial, J.S. Koo, N.T. Eissa, Ubiquitination of inducible nitric oxide synthase is required for its degradation, Proc. Natl. Acad. Sci. USA 99 (2002) 12315-12320.

[29] A. Musial, N.T. Eissa, Inducible nitric-oxide synthase is regulated by the proteasome degradation pathway, J. Biol. Chem. 276 (2001) 24268-24273.

[30] S. Ghosh, M. Karin, Missing pieces in the NF-אB puzzle, Cell 109 (2002) S81S96.

[31] H.L. Pahl, Activators and target genes of Rel/NF- $\kappa B$ transcription factors, Oncogene 18 (1999) 6853-6866.

[32] J.C. Fernandes, J. Martel-Pelletier, J.P. Pelletier, The role of cytokines in osteoarthritis pathophysiology, Biorheology 39 (2002) 237-246.

[33] M.N. Farahat, G. Yanni, R. Poston, G.S. Panayi, Cytokine expression in synovial membranes of patients with rheumatoid arthritis and osteoarthritis, Ann. Rheum. Dis. 52 (1993) 870-875.

[34] V. Moos, S. Fickert, B. Müller, U. Weber, J. Sieper, Immunohistological analysis of cytokine expression in human osteoarthritic and healthy cartilage, J. Rheumatol. 26 (1999) 870-879. 